\title{
Analisa Pengaruh Penambahan Bioetanol pada Bensin terhadap Sifat Volatilitas
}

\author{
Ghuzrina Prihandini, Eliana Stefani, Rifana Indrawijaya \\ Program Studi Teknik Kimia, Akademi Minyak dan Gas Balongan Indramayu \\ ghuzrinaprihandini@yahoo.com
}

\begin{abstract}
Abstrak
Tujuan dari penelitian, adalah untuk meminimalisir penggunaan bensin dengan cara penambahan bahan bakar alternatif yang lebih ramah lingkungan, mengingat semakin menipisnya cadangan bahan bakar fosil. Salah satu solusinya adalah dengan cara blending bensin dasar 88 dengan bioetanol. Metode yang digunakan antara lain ASTM D 86 untuk destilasi, ASTM D 323 untuk Reid Vapor Pressure (RVP), ASTM D 525 untuk oksidasi stabilisasi. Variabel konsentrasi meliputi bensin dasar 88, blending bensin dengan etanol ( E2,5\% ; E5\% ; $\mathrm{E} 7,5 \% ; \mathrm{E} 10 \% ; \mathrm{E} 12,5 \%$; E15\% ; E17,5\% ; E20\%) dan etanol murni. Proses distilasi digunakan untuk mengetahui sifat volatilitasnya berdasarkan kurva distilasinya. Dari penelitian ini, diperoleh nilai uji densitas, uji stabilisasi oksidasi, uji RVP sebesar $801 \mathrm{~kg} / \mathrm{m} 3,<\mathrm{E} 10 \%$, $50 \mathrm{kPa}$ secara berurutan. Hasil optimum diperoleh pada campuran bensin-bioetanol E10\%.
\end{abstract}

Kata kunci: bahan bakar alternatif, bioetanol, distilasi, volatilitas.

\section{PENDAHULUAN}

Krisis energi menjadi isu penting dalam beberapa tahun terakhir dan menjadi fokus investigasi dari banyak negara diseluruh dunia. Dengan kondisi seperti ini, dimana bahan bakar minyak semakin lama semakin menipis, bioetanol hadir sebagai solusi bahan bakar alternatif pengganti bensin. Selain itu, Indonesia merupakan penghasil bioetanol keempat terbesar di dunia setelah Amerika, Argentina dan Brazil dengan jumlah meningkat dari 526,74 juta liter pada tahun 2012 menjadi 1033,83 juta liter pada tahun 2015 [1]. Sebagai tindak lanjut dari Peraturan Presiden (Perpres) No.5 Tahun 2006 tentang kebijakan energi nasional, untuk mengurangi ketergantungan pada bahan bakar fosil maka bioetnol merupakan sumber energi yang menjanjikan. Bioetanol sebagai energi memiliki nilai oktan yang tinggi sebesar 129 sehingga pembakarannya relatif stabil dan sempurna yang dapat mengurangi emisi karbon monoksida. Bioetanol juga memiliki kandungan oksigen yang cukup tinggi sebesar 35\% yang dapat menghasilkan pembakaran yang bersih (emisi karbon monoksida lebih rendah 19-25\% dari bensin). Dari spesifikasi yang dimiliki bioetanol diatas, energi terbarukan ini memiliki potensi yang cukup besar sebagai bahan bakar alternative untuk mensubtitusi BBM, khususnya bensin. Oleh karena itu, pada penilitian ini dimaksudkan untuk mengetahui persen komposisi blending bioetanol dengan bensin terhadap sifat volatilitasnya.

\section{TINJAUAN PUSTAKA}

Bioetanol merupakan istilah dari etanol yang berasal dari serangkaian proses pengolahan bahan-bahan hayati yang mengandung karbohidrat seperti ubi kayu, sagu, jagung, molase(sari tetes tebu) dll. Bioetanol dimanfaatkan dalam industri kosmetik, parfum, farmasi, sebagai pelarut maupun energi. Bioetanol atau ethyl alcohol $\mathrm{C}_{2} \mathrm{H}_{5}(\mathrm{OH})$ adalah cairan yang tidak berwarna, memiliki titik didih $78,4^{\circ} \mathrm{C}$, tidak mudah menguap dan biodegradable [2].

Bioetanol dapat dipakai untuk beberapa kegunaan 1) sebagai komponen yang mempunyai angka oktan, untuk konsentrasi tidak lebih dari 5\% digunakan untuk motor gasoline. 2) untuk konsentrasi yang tidak melebihi $10 \% \mathrm{v} / \mathrm{v}$ digunakan untuk produksi benzanol (gasohol) 3) untuk konsentrasi yang lebih dari 10\% v/v ( sampai dengan 85\% v/v) digunakan untuk ETBE (ethyl tertiary butyl ether) [3].

Bioetanol merupakan salah satu bahan bakar alternatif yang diproduksi dari bahan baku terbarukan dan merupakan senyawa oksigen yang paling sering diuji sebagai komponen bahan bakar baik untuk percikan maupun untuk kompresi mesin pengapian. Jenis alkohol ini mempengaruhi sifat bahan bakar dan mengurangi substansi berbahaya dari gas buang knalpot karena kandungan oksigen dalam molekulnya [4].

Bioetanol umumnya ditambahkan pada bensin untuk menambahkan nilai oktan dan mereduksi polusi karbon monoksida dari gas buang knalpot (Pumphrey, 2000). Bioetanol bisa digunakan sebagai biokomponen maupun untuk bahan bakar murni. 
Campuran alkohol dengan bensin telah banyak diteliti di berbagai belahan dunia. Pada tahun 1975, Brazil memulai program pemerintahnya untuk memproduksi bioetanol sebagai bahan bakar substitusi karena mahalnya harga bensin (De, 2011). Saat ini, di Eropa, campuran bioethanol dengan bensin bisa mencapai 10\% v/v [5].

Saat ini, beberapa penelitian tentang bahan bakar menggunakan kurva distilasi sebagai dasar penentuan sifat volatiltas, termasuk juga pada penelitian ini.distilasi merupakan metode pemisahan campuran berdasarkan vapor-liquid equilibrium (VLE). Dengan metode ASTM D86 sangat memungkinkan untuk mengetahui kompleksitas dari blending bensin-bioetanol yang berkaitan langsung dengan volatilitas dari komposisi sampel.

Salah satu property yang mempengaruhi proses pembakaran dan emisi mesin adalah volatilitas bahan bakar. Pada bahan bakar bensin, uji volatilitasnya untuk stadar kualitas menggunakan Reid Vapor Pressure (RVP) sedangkan untuk bahan bakar lainnya menggunakan kurva distilasi. Kurva distilasi menggambarkan temperatur titik didih campuran melawan fraksi volum distilat. Initial dan Final Boiling Point (IBP dan FPB, T10 (10\% volum distilat) T50, T90 merupakan titik representatif pada kurva. Sebagai contoh, T10 merupakan awal dari volum destilat sedangkan keberadaan komponen berat bahan bakar terletak pada T90 [6].

Dalam produksi bahan bakar, tekanan uap perlu diukur karena berpengaruh pada proses transportasi, penyimpanan dan produksi untuk menghindari kecelakaan dan meminimalisir loss karena evaporasi. Bahan bakar dengan dengan tekanan uap tinggi mempunyai komponen yang volatil yang tinggi juga. Takaeshita meneliti tentang penambahan pelarut organik pada rasio yang berbeda (> 50\% v/v) dapat memodifikasi nilai tekanan uap [7]

Pada tahun 2007, Agarwal meneliti campuran bensinbioetanol sampai 20\% v/v dapat langsung digunakan tanpa harus memodifikasi mesin. Penggunaan biofuel dengan jumlah kandungan bioethanol lebih tinggi akan memerlukan perubahan konstruksi mesin. Perubahan ini mengakibatkan dari antara lain, suhu yang lebih tinggi dari pengapian campuran airbioethanol di ruang bakar dibandingkan dengan campuran dengan minyak diesel. Pengembangan performa mesin sangat memungkinkan dengan rasio kompresi lebih tinggi $( \pm 24)$ dalam mesin berbahan bakar bioethanol dibandingkan dengan rasio kompresi mesin berbahan bakar bensin $( \pm 17)[8]$.

Telah diketahui bahwa mesin berbahan bakar fosil didesain dengan efisiensi pembakaran yang tinggi. Namun demikian mesin memiliki beberapa kekurangan, salah satunya adalah polusi emisi yang tinggi dan mengandung substansi yang berbahaya termasuk zat partikulat dan NOx yang dihasilkan selama proses pembakaran [9]. Hal ini juga dibuktikan oleh beberapa peneliti bahwa dengan penambahan bioetanol pada bensin menghasilkan substansi berbahaya lebih rendah pada emisi gas buang[10]. Penambahan bioetanol pada bensin pada konsentrasi $10 \%$ dan 30\% bias mereduksi asap namun mempengaruhi polutan yang lain tergantung dari kondisi operasi mesin [11]. Peneliti lainnya, campuran bioetanol-bensin pada $10 \%$ dan $15 \%$ v/v dapat menurunkan zat partikulat pada emisi gas buang sebesar $20 \%$ dan $30 \%$ secara berturut-turut [12].

\section{METODE PENELITIAN}

\subsection{Alat dan Bahan}

Bioetanol, bensin, gas $\mathrm{O} 2$ dan beberapa solvent diambil dari sumber komersil. Seperangkat alat destilasi dari merk Tanaka sedangkan alat uji densitas, chamber dan vessel dari Parr instrument. Sampel yang akan digunakan, disimpan pada botol polietilen dan diisolasi kemudian didinginkan pada temperatur 8-15 0C untuk menghindari penguapan dari komponen yang volatil. Pada penelitian ini menguji bensin dasar 88 (E0\%), bioetanol murni (E100\%) dan beberapa blending bensinbioetanol diantaranya E2,5\%; E5\%; E7,5\% ; E10\% ; E12,5\% ; E15\% ; E17,5\% ; E20\%. Penamaan pada blending menunjukkan persen komposisinya, misalkan E20\% menunjukkan komposisi: $20 \%$ bioetanol dan 80\% bensin dasar 88 . Dari proses distilasi diperoleh IBP, T10 (10\% volum distilat ) sampai dengan T90 dan FBP.

\subsection{Prosedur Distilasi}

Percobaan distilasi dilakukan pada tekanan atmosferis menggunakan seperangkat alat destilasi dengan mengikuti prosedur pada ASTM D86. Untuk tes analisa , $100 \mathrm{~mL}$ sampel yang didinginkan sebelumnya diletakkan pada spesifik distilation flask coupled untuk di sensor dan dipanaskan dengan rate ditilasi sebesar 4-5 mL/menit. Uap yang terdistilasi terkondensasi dan dikumpulkan pada beaker glass sehingga diperoleh kurva distilasi.

\subsection{Pengujian Reid Vapor Pressure (RVP)}

Pengujian RVP dengan menggunakan metode ASTM D 323. Aquades dipanaskan mencapai suhu konstan 40 0C pada bak pemanas. Memasukkan sampel pada gasoline chamber yang telah didinginkan sebelumnya. Gasoline chamber dihubungkan dengan vapor chamber kemudian digoyangkan sebanyak 8 kali. Sampel yang telah digoyangkan dipanaskan selama 5 menit. Tekanan diukur menggunakan pressure gauge. Langkah ini diulang 3 kali sampai diperoleh tekanan yang konstan.

\subsection{Oksidasi Stabilitas}

Sampel yang akan dianalisa diletakan pada glass sample yang telah disterilisasi menggunakan toluene dan aceton pada suhu 100 0C dan dimasukkan kedalam pressure vessel dan dinjeksi O2 hingga tekanan mecapai 690-705 kPa. Pressure vessel kemudian dimasukkan oxidation dry bath untuk dianalisa. 


\section{HASIL DAN PEMBAHASAN}

\subsection{Densitas}

Blending merupakan parameter kunci yang menentukan campuran bensin-bioetanol dengan konsentrasi E0\%- E100\% sebagai bahan bakar. Oleh karena itu beberapa sifat diuji terlebih dahulu, seperti densitas. Densitas merupakan salah satu property bahan bakar yang sangat penting karena mempengaruhi proses produksi, transportasi dan distribusi bahan bakar. Dengan alasan tersebut, maka keakuratan densitas bahan bakar menjadi hal yang penting untuk perhitungan konsumsi energi karena mempengaruhi massa dan injeksi bahan bakar dan heating value[13]. Pada Tabel. 1 menunjukkan bahwa semakin banyak konsentrasi etanol yang ditambahkan kedalam bensin maka densitasnya juga semakin kecil. Semakin besar penambahan etanol kedalam premium maka densitas blending juga akan bergeser ke arah densitas etanol

Tabel 1.Densitas blending bensin-bioetanol pada berbagai konsentrasi

\begin{tabular}{cc}
\hline Konsentrasi & Densitas $\left(\mathrm{kg} / \mathrm{m}^{3}\right)$ \\
\hline E0\% & 812 \\
E2.5\% & 810 \\
E5.0\% & 807 \\
E7.5\% & 805 \\
E10\% & 801 \\
E12.5\% & 797 \\
E15\% & 794 \\
E17.5 & 791 \\
E20\% & 790 \\
E100\% & 776 \\
\hline
\end{tabular}

4.2 Distilasi

Densitas bersama dengan tekanan uap, difusivitas uap dan tegangan permukaan mempengaruhi struktur spray bahan bakar, pembakaran dan karakteristik emisi. Dari hasil percobaan Gambar 1 mengindikasikan untuk uji temperatur awal penguapan (IBP) pada berbagai konsentrasi bahwa temperatur IBP campuran bensin-etanol hanya sampai <E10\% yang masih mendekati IBP bensin murni. Selebihnya diatas konsentrasi >E15\% mempunyai tren meningkat seiring dengan meningkatnya konsentrasi etanol. Hal ini juga sesuai dengan penelitian Odziemkowska, bahwa penambahan etanol kedalam premium cenderung akan menaikkan temperatur awal penguapan. Semakin besar penambahan etanol kedalam premium, maka IBP campuran akan menuju IBP etanol. Karena etanol mempunyai gugus - $\mathrm{OH}$ maka mempunyai titik didih lebih tinggi dibandingkan dengan bensin dasar 88 .

Dari Gambar 2 menunjukkan proses distilasi blending bioetanol-bensin dimana mempunyai tren naik seiring dengan naiknya temperatur terkecuali pada etanol murni. Hasil optimum diperoleh pada konsentrasi E10\% karena masih mendekati dengan sifat properties bensin murni. Pada Gambar 2, hasil pengujian distilasi yang dinyatakan memenuhi standar spesifikasi SK Dirjen Migas No. 933 K/10/DJM.S/2013 pada distilasi 10\% volume penguapan, 50\% volume penguapan, $90 \%$ volume penguapan, FBP adalah bensin dasar 88 (E0\%) dan blending E2,5\%, E5\%, E7,5\% dan E10\%.

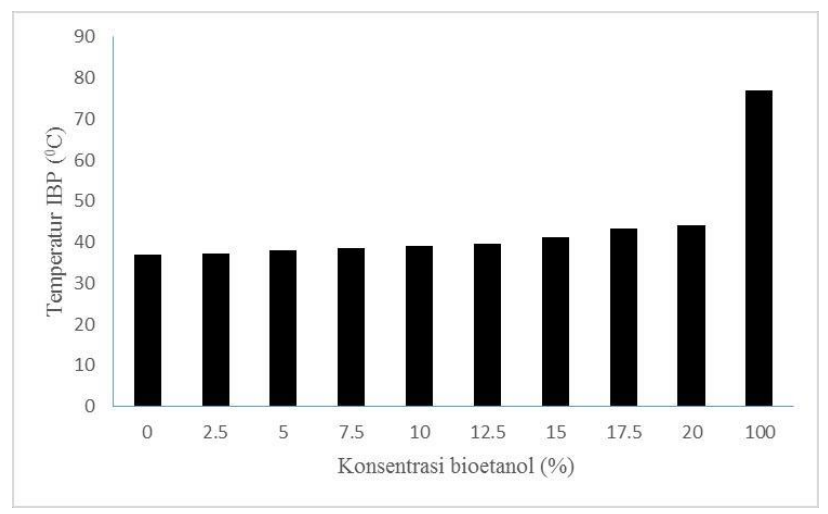

Gambar 1. Pengaruh konsentarsi bioetanol terhadap nilai IBP

Peneliti lain, Lapuerta (2015) juga memperoleh hasil yang sama sebesar 10\% untuk penambahan etanol kedalam besin. Proses distilasi berawal dari temperatur IBP kemudian menuju ke final boiling point etanol berkisar $780 \mathrm{C}$ (tergantung dari tekanan ambient) yang mengakibatkan volatilitas etanol lebih tinggi daripadi bensin. Etanol juga merupakan komponen yang paling dahulu terdistilasi. 


\subsection{Reid Vapor Pressure (RVP)}

Pada Gambar.3 menunjukkan bahwa pengaruh konsentrasi bioetanol terhadap RVP cenderung menurun seiring dengan meningkatnya konsentrasi bioetanol. Dari hasil yang diperoleh RVP tertinggi pada E5\% yaitu sebesar 61,36 kPa, diatas konsentrasi tersebut nilai RVP berangsurangsur menurun. Untuk konsentrasi E7,5\% dan E10\% masing-masing sebesar 52,1 $\mathrm{kPa}$ dan $50 \mathrm{kPa}$. Nilai tekanan uap tertinggi terjadi pada konsentrasi atau fraksi awal kemudian berangsur-angsur menurun. Hal ini mengindikasikan bahwa konsentrasi awal mengandung hidrokarbon ringan yang mempunyai tekanan uap lebih tinggi (Mendez, 2016). Selain itu, karena masih adanya kandungan air dalam bioetanol yang digunakan dalam percobaan ini sehingga semakin banyak volum bioetanol yang dicampurkan maka jumlah air yang terikut juga akan semakin bertambah besar.

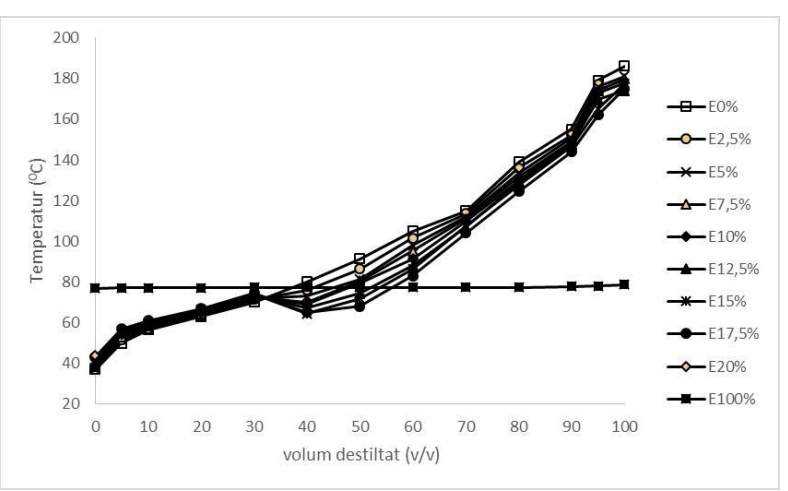

Gambar 2. Kurva distilasi blending bensin-bioetanol

Hal ini mengakibatkan nilai tekanan uap semakin rendah, dikarenakan oleh sifat air yang lebih susah menguap dibandingkan dengan bensin dan bioetanol. Dalam segi keamanan penyimpanan bensin harus memenuhi standar tekanan uap maksimum bensin yaitu sebesar $69 \mathrm{kPa}$ dan tekanan uap minimum $45 \mathrm{kPa}$. Dari hasil sampel pengujian semua sampel telah memenuhi standar untuk tekanan uap maksimu, namun untuk tekanan uap minimum hanya bensin dasar 88 dan blending dengan konsentrasi $<\mathrm{E} 10 \%$ saja yang lolos standar minimal nilai tekanan uap.

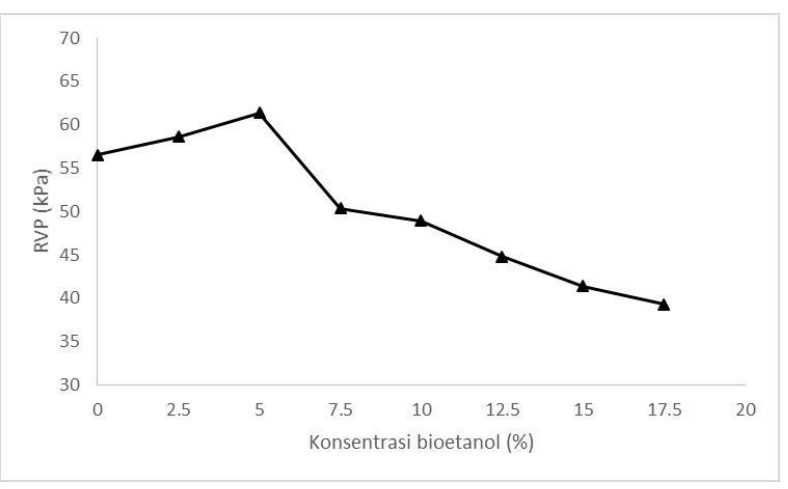

Gambar. 3 Pengaruh konsentrasi bioetanol terhadap RVP

\subsection{Stabilitas Oksidasi}

Uji stabilitas oksidasi optimum hingga penambahan E10\% stabilitas oksidasi masih memenuhi standar spesifikasi pemerintah, yaitu masih >360 menit, namun ketika penambahan lebih dari 10\% stabilitas oksidasi semakin rendah, dapat dilihat pada Gambar 4. Jika stabilitas oksidasi semakin rendah maka berpengaruh terhadap daya torsi yang menurun, pembakaran yang tidak sempurna.

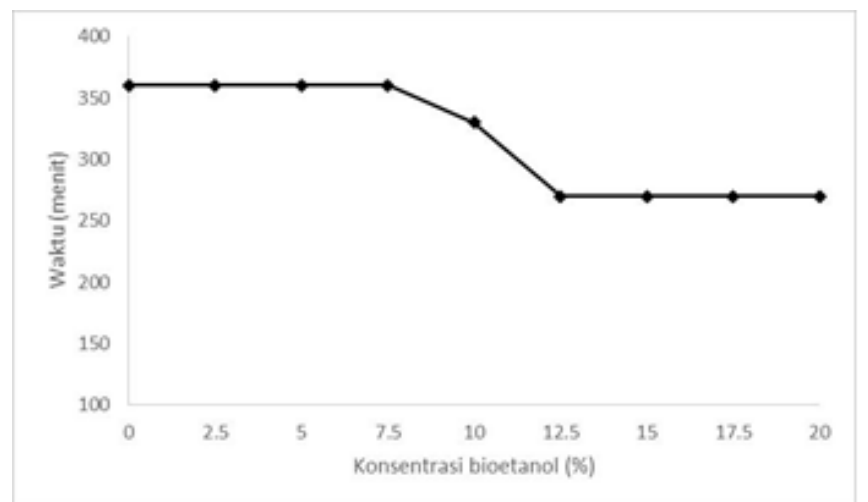

Gambar.4 Pengaruh konsentrasi bioetanol terhadap Stabilitas oksidasi 
Stabilitas oksidasi juga merupakan salah satu indikasi terjadinya interaksi kimia pada distilasi blending bensinbioetanol .Polaritas merupakan perbedaan elektronegatifan diantara atom-atom di dalam gugus. Semakin besar perbedaan elektronegatifan maka semakin besar pula polaritasnya. Penggunaan etanol pada penelitian ini, polaritas terletak pada gugus hidroksil (-OH) yang merupakan gugus kimia paling polar. Dengan kata lain, penambahan volum konsentrasi etanol kedalam bensin, maka gugus hidroksilnya semakin besar karena struktur molekulnya lebih pendek. Sedangkan bensin merupakan campuran komponen kimia yang kompleks, dari senyawa alkana yang non polar sampai senyawa polar aromatik hidrokarbon. Di dalam blending, senyawa aromatik sedikit berinteraksi dengan gugus polar hidroksil pada etanol dan membentuk momen dipol sementara. Minimumnya interaksi antara etanol dan diesel menjadikan campuran ini stabil saat proses distilasi. Konsentrasi etanol yang rendah didalam blending bensin-bioetanol, senyawa aromatis hidrokarbon terlarut kedalam etanol, yang membuat campuran ini stabil. Penambahan konsentrasi etanol kedalam campuran masih bisa stabil selama masih ada senyawa aromatis yang terlarut kedalam etanol.

\section{KESIMPULAN}

Hasil pengujian distilasi yang dinyatakan memenuhi standar spesifikasi pada distilasi $10 \%$ volume penguapan, $50 \%$ volume penguapan, 90\% volume penguapan, FBP adalah bensin dasar 88 (E0\%) dan blending E2,5\%, E5\%, E7,5\% dan E10\%. Dari pengujian distilasi, didapatkan bahwa penambahan bioetanol dalam bensin premium 88 telah mempengaruhi hasil temperature pada $10 \%$ volume penguapan. Sedangkan untuk uji RVP dan stabilitas oksidasi diperoleh hasil terbaik masing-masing sebesar E5\% dan E10\%. Sehinga dapat dikatakan secara keseluruhan penambahan etanol bisa sampai E10\%, yang merupakan konsentrasi optimum untuk blending bensinbioetanol.

\section{DAFTAR PUSTAKA}

[1] OECD, “Organization for Economic Co-operation and Development," Agric. Outlook, 2015.

[2] A. W, Dinamika pengembangan industri bioetanol di Indonesia. Teknologi Proses, 2014.

[3] E. M. G. E, "Prospect of bioethanol fuels E30 and E85 application in Rusia and technical requirements for their quality," Renew. Sustain. Energi Riviews, vol. 66, pp. 228-232, 2016.

[4] C. J. ODZIEMKOWSKA M, MATUSZEWSKA A, "Diesel oil with bioethanol as a fuel for compressionignition engines," Appl. Energy, 2016.

[5] B. H. BALAT M, "Recent trends in global productions and utilization of bioethanol fuel," Appl. Energy, vol. 86, pp. 2273-82, 2009.

[6] F. J. LAPUERTA M, "Molecular interaction in blends of alcohol with diesel fuels : Effect on stability and distillation," Fuel, pp. 167-172, 2015.

[7] R. TAKAESHITA EV, "Influence of solvent addition on the physyco-chemical properties of Brazilian gasoline," vol. 87, pp. 2168-77, 2008.

[8] S. K. KARTHIKEYAN B, "Performance characteristic of a glow pug assisted low heat diesel engine using ethanol.," Appl. Energygy, vol. 88, no. 323-329, 2011.

[9] K. A. ASLAN R, ALTIMIS K, "The pollutant emissions from diesel engine vehicles and exhaust after treatment system.," Clean technol Env., vol. 17, pp. 15-27, 2015.

[10] H. Z. ZHU L, CHEUNG Z, "Combustion performance and emissions characteristic of a diesel engine fueled with ethanol-biodiesel blend.," Fuel Charact., vol. 90, p. 174350, 2011.

[11] S. J. KASS MD, THOMAS JF, "Emissions from a 5.9 L diesel engine fueled with ethanol diesel blend," Tech. Pap., vol. 1, 2001.

[12] P. R. McCORMICK RL, "Advance petroleum base fuel program and removable diesel program," in $N E R L / M P$ $540,2001$.

[13] R.-V. DKK, “A predicting cetan number, kinematic viscosity, density and higher heating value of biodiesel from its fatty acid methyl ester composition," Fuel, p. .102-111, 2012. 